\title{
1D AND 3D ANALYSES OF THE ZY2 SCIP BWR RAMP TESTS WITH THE FUEL CODES METEOR AND ALCYONE
}

\author{
J. SERCOMBE*, M. AGARD, C. STRUZIK, B. MICHEL, G. THOUVENIN, C. POUSSARD ${ }^{1}$ and K. R. KÄLLSTRÖM² \\ CEA, DEN, Fuels Studies and Modelling Section, F-13108 Saint-Paul-lez-Durance, France \\ ${ }^{1}$ CEA, DEN, F-91191 Gif-sur-Yvette, France \\ ${ }^{2}$ Studsvik Nuclear AB, SE-611 82 Nyköping, Sweden \\ *Corresponding author. E-mail : jerome.sercombe@cea.fr
}

Received January 16, 2009

Accepted for Publication January 23, 2009

In this paper, three power ramp tests performed on high burn-up Re-crystallized Zircaloy2 - UO2 BWR fuel rods (56 to $63 \mathrm{MWd} / \mathrm{kgU}$ ) within the SCIP project are simulated with METEOR and ALCYONE 3D. Two of the ramp tests are of staircase type up to Linear Heat Rates of 420 and $520 \mathrm{~W} / \mathrm{cm}$ and with long holding periods. Failure of the $420 \mathrm{~W} / \mathrm{cm}$ fuel rod was observed after 40 minutes. The third ramp test consisted of a more standard ramp test with a constant power rate of 80 $\mathrm{W} / \mathrm{cm} / \mathrm{min}$ up to $410 \mathrm{~W} / \mathrm{cm}$ with a short holding time. The tests were first simulated with the METEOR 1D fuel rod code, which gave accurate results in terms of profilometry and fission gas releases. The behaviour of a fuel pellet fragment and of the cladding piece on top of it was then investigated with ALCYONE 3D. The size and the main characteristics of the ridges after base irradiation and power ramp testing were recovered. Finally, the failure criteria validated for PWR conditions and fuel rods with low-to-medium burn-ups were used to analyze the failure probability of the KKL rodlets during ramp testing.

KEYWORDS : Fuel Rod, Pellet Cladding Interaction (PCI), Modeling, 3D, Light Water Reactor, Ramp Test

\section{INTRODUCTION}

This study is concerned with the modelling of fuel behaviour and of Pellet Cladding Mechanical Interaction (PCMI) in Light Water Reactors (LWR). Failures due to Pellet-Cladding Interaction (PCI), as discovered in the early 1970's, can be avoided in Light Water Reactors (LWRs) thanks to optimized plant operational procedures and fuel management schemes. However, research and development programs on this topic are still undertaken worldwide in an effort to improve the understanding of the mechanisms that can lead to PCI failure. Among them, the international Studsvik Cladding Integrity Program (SCIP) was initiated in 2002 as an OECD/NEA project with the aim of identifying and quantifying the important mechanical parameters and material properties of medium to high burn-up cladding with respect to mechanisms with potential impacts on fuel failure during normal operation and anticipated transients [1]. The program comprises several parts concerned with hydride embrittlement (HE), delayed hydrogen cracking (DHC) and stress corrosion cracking (SCC) under PCMI. Dedicated laboratory experiments and power ramp tests [2] (five on PWR fuel rods and five on BWR) are currently underway or have been undertaken in Studsvik to study more precisely each type of failure mechanism.
To model PCI in LWRs, two separate applications termed METEOR [3] and ALCYONE [4] have been developed at the Atomic Energy Commission (CEA) over the last two decades. METEOR is based on a onedimensional axi-symmetric description of the radial dimension of the fuel element, associated to a discrete axial decomposition of the fuel rod in stacked independent fuel "slices". The one-dimensional METEOR code is used to assess the global geometrical changes of the fuel rod during irradiation and to estimate the behavior of fission gases generated by irradiation up to high burn-up levels. However, it is not sufficient to estimate precisely the local stresses in the cladding resulting from PCMI. Only a more detailed description of the thermo-mechanical behavior of the fuel pellet and of the cladding, based on 2D or 3D Finite Element analyses, can provide detailed information on this point.

This has prompted the development of the multidimensional PWR fuel applications TOUTATIS [5] and ALCYONE [4], the latter in the framework of the PLEIADES [6] environment. The main aspects of the 3D model of ALCYONE, i.e., the geometry of the meshed fuel pellet fragment, the boundary conditions, the loading applied to the pellet and the cladding, the thermomechanical coupling, the material laws used to describe fuel cracking and cladding creep-plasticity, and the friction 
at the pellet-cladding interface are detailed in reference 7. Of particular interest in this study concerned with high burn-up fuel rods are the fission gas models of the METEOR $1 \mathrm{D}$ code, which were recently introduced in ALCYONE [8], and a specific iterative loop developed to couple fission gas swelling (which depends on the hydrostatic pressure) to the thermo-mechanical solution of the 3D problem (which depends on gas-induced swelling). The fission gas models account for intra-granular bubble growth, coalescence and migration, for inter-granular bubble growth and migration, for gas transport in the porosity and for gas release in the plenum.

In this paper, three power ramp tests performed on high burn-up Re-crystallized Zircaloy 2 - UO2 BWR fuel rods (56 to $63 \mathrm{MWd} / \mathrm{kgU}$ ) within the SCIP project were simulated with METEOR and ALCYONE 3D. Two of the ramp tests are of staircase type up to Linear Heat Rates of 420 and $520 \mathrm{~W} / \mathrm{cm}$ and with long holding periods. Failure of the $420 \mathrm{~W} / \mathrm{cm}$ fuel rod was observed after 40 minutes. The third ramp test was a more standard ramp test with a constant power rate of $80 \mathrm{~W} / \mathrm{cm} / \mathrm{min}$ up to $410 \mathrm{~W} / \mathrm{cm}$ and with a short holding time. No failure of the fuel rod was observed in this test. The aim of this paper is twofold: first to demonstrate the usefulness and consistency of 3D pellet-cladding detailed calculations with respect to 1D fuel rods simulations and experimental profilometries, and second to analyze Studsvik experimental

Table 1. Main Geometrical and Physical Properties of the Rodlets

\begin{tabular}{l|c}
\hline Cladding & Zry2 with liner \\
\hline Type & $9.62 \mathrm{~mm}$ \\
Outer diameter & $8.36 \mathrm{~mm}$ \\
Inner diameter & \\
\hline Fuel Pellet & $\mathrm{UO}_{2}$ \\
\hline Type & $8.19 \mathrm{~mm}$ \\
Diameter & $8.7 \mathrm{~mm}$ \\
Height & $5.59 \mathrm{~mm}-0.13 \mathrm{~mm}$ \\
Dish diameter - depth & $0.1 \mathrm{~mm}-0.25 \mathrm{~mm}$ \\
Chamfer depth - width & $11 \mu \mathrm{m}$ \\
Initial grain diameter & $4.5 \%$ \\
U-235 enrichment & $96.1 \%$ \\
Density ratio & $63-67-56 \mathrm{MWd} / \mathrm{kgU}$ \\
Local burn-up (ramp rodlet) & \\
\hline Rod & $\mathrm{He}-0.8 \mathrm{MPa}$ \\
\hline Internal gas pressure & $2.132 \mathrm{~cm}{ }^{3}$ \\
Free volume & $313.2 \mathrm{~mm}(36 \mathrm{pellets})$ \\
Fuel stack length &
\end{tabular}

data on PCMI in BWR conditions and high-burn-up cladding using fuel codes and failure criteria validated for PWR conditions and fuel rods with low-to-medium burn-ups.

\section{DESCRIPTION OF THE POWER RAMP TESTS}

In SCIP, cladding failure mechanisms are studied. The main mechanisms are Stress corrosion cracking (SCC), Hydrogen Embrittlement (HE) and Delayed Hydrogen cracking (DHC). The primary driving force for the three mechanisms is Pellet Cladding Mechanical Interaction (PCMI). One essential approach of PCMI within SCIP is ramp testing. Before the shutdown of the $\mathrm{R} 2$ reactor in 2005 , ten rodlets were ramp tested. The main goal was, among others, to evaluate the fuel dimensional changes in relation to reactor conditions, time and LHR. Five tests were performed on PWR material and five on BWR. The burn-up of the rodlets was in the range 40 to $76 \mathrm{MWd} / \mathrm{kgU}$. Several ramp types with different holding times were used, which has provided a basis for evaluating the strain changes during the holding time.

In June of 2006, a modelling workshop on the three ramp tests performed on BWR Zircaloy-2 rodlets termed KKL 1-3 [9] was held at Studsvik. The main geometrical and physical properties of the rodlets are given in Table 1. The dimensions are fairly similar to those of standard fuel rods for PWR except for the height of the fuel pellets $(8.7 \mathrm{~mm})$, which was in this case approximately $50 \%$ shorter. The initial fuel pellet - cladding gap was $85 \mu \mathrm{m}$.

The idealized power histories during base irradiations and power ramp tests (given at the maximum LHR) are plotted in Figs. 1-2, respectively. The coolant pressure was $7 \mathrm{MPa}$ during the base irradiations and 9.3 $\mathrm{MPa}$ during the power ramp tests. The base irradiations of the

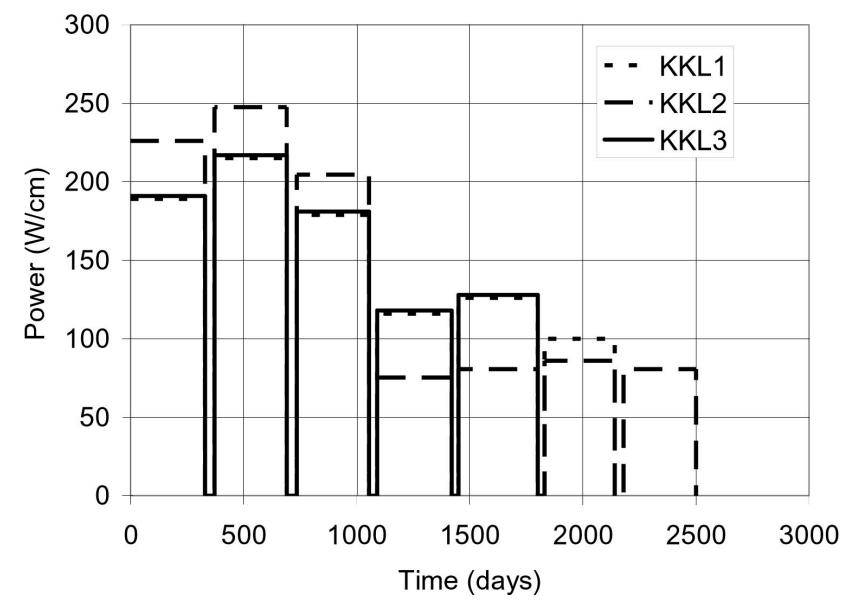

Fig. 1. Power History during Base Irradiation 
KKL1, KKL2 and KKL3 rods were 6, 7 and 5 cycles long, respectively, at a LHR value that was between 50 and $200 \mathrm{~W} / \mathrm{cm}$. The LHR profiles along the rodlets were almost flat. The KKL1 staircase ramp failed after $40 \mathrm{~min}$ at $420 \mathrm{~W} / \mathrm{cm}$ with several axial cracks around the power peak position. Visual inspection and microscopy indicate that wall-through cracks were initiated on the outside. The KKL2 rod was tested at a constant rate of $80 \mathrm{~W} / \mathrm{cm} / \mathrm{min}$ and with a short holding time of 30 seconds. The purpose was to examine any holding time effect on the residual strain. The KKL3 rod was tested with a staircase ramp up to $520 \mathrm{~W} / \mathrm{cm}$, after which it was held for 12 hours without failure. The maximum residual strain of this rod was approximately $1.8 \%$.

The ramp rodlets were mounted in a vertically nonsymmetric position in the reactor. Thus, the gradient in thermal flux allowed an expanded LHR range along the rod, resulting in a varying residual strain (measured by means

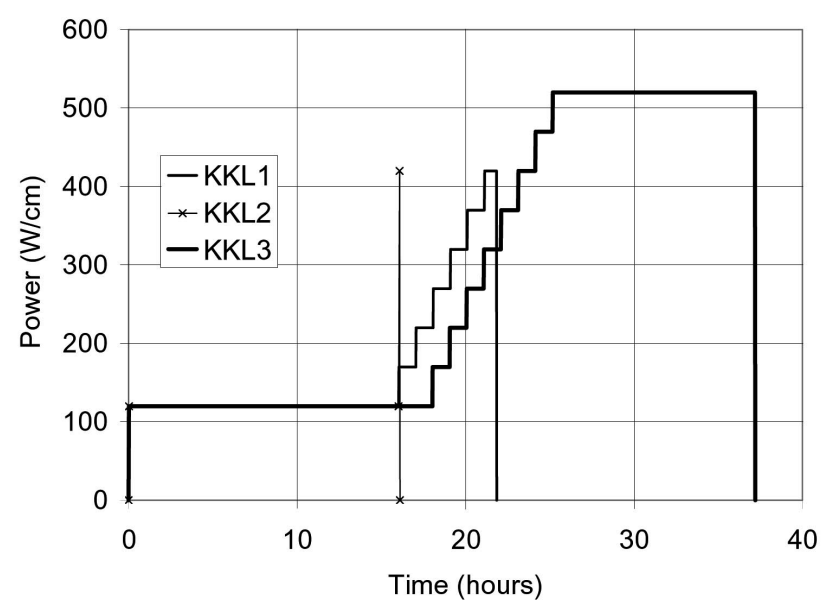

Fig. 2. Power History during Power Ramp Tests

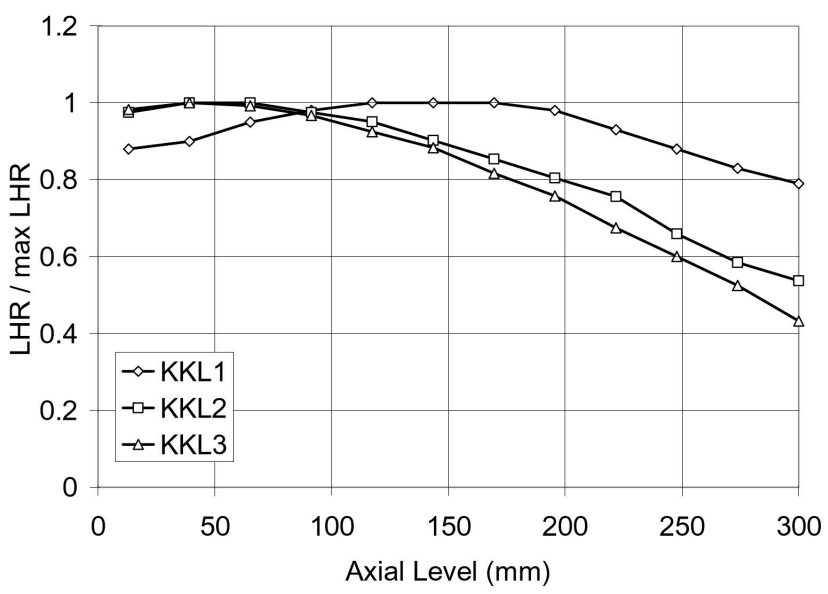

Fig. 3. Normalized LHR Profiles during the Power Ramp Tests of profilometry before and after the ramp). The normalized LHR profiles (with respect to the maximum LHR in the ramp tests) are given for the three rodlets in Fig. 3.

\section{MAIN HYPOTHESES IN THE SIMULATIONS WITH METEOR AND ALCYONE 3D}

The 1D METEOR simulations were performed with an axial discretization of the rodlets in 12 segments and a radial discretization of each segment in 30 elements. The liner was included in the cladding thickness $(630 \mu \mathrm{m})$ and is assumed to behave as the cladding. The main phenomena considered in the 1D simulations are:

- Irradiation creep, thermal creep and plasticity of Zr2 during base irradiation and power ramp testing.

- Thermal and irradiation creep and radial cracking of the fuel pellet according to a creep-damage material law [10].

- Evolution of the thermal and mechanical properties of the materials with temperature, porosity and burn-up.

- Coupled thermo-mechanical analysis of the fuel pellet gap - cladding system (the gap size depends on the deformation of the rodlet and on the FG release).

- Generation of, diffusion of FGs in intra-granular, intergranular and connected pores, and release of FGs in the plenum (internal pressure update).

- Pellet densification, pellet FG-induced swelling.

- Relocation of pellet fragments after the pellet cladding contact.

- Development of an external rim with specific properties (gas diffusion, FG swelling, ...)

Here, fuel cracking and fuel relocation are treated as separate phenomena with distinct kinetics. Fuel relocation is based on 3D calculations performed with TOUTATIS [5].

In the 3D FE model of ALCYONE, only half of a single pellet fragment and the overlying piece of cladding (see Fig. 4) are meshed. The fuel pellet considered in the simulations is located axially at the maximum LHR. The size of the pellet fragment is consistent with post-irradiation examinations performed on PWR pellets after 2 or 3 cycles of base irradiation, which show the existence of 4 to 8 pellet fragments in the circumferential direction. The pellet fragment angle $\left(22.5^{\circ}\right)$ was chosen in order to maximize the magnitude of the fragment "hourglass" shape under irradiation. The pellet-cladding system is meshed with approximately 1500 solid quadrangles with 8 nodes.

The boundary conditions considered in the 3D calculations are shown in Fig. 4. They account for the geometrical symmetries of the problem and for the pelletcladding and pellet-pellet interactions. At the inter-pellet plane (plane $0 \mathrm{x}_{0} \mathrm{y}_{0}$ in Fig. 4), unilateral contact conditions are prescribed $(\mathrm{Uz} \geq 0)$. The mechanical reaction of the fissile column above and under the meshed fragment is represented by a kinematics relationship between the pellet and the cladding mid-planes (plane $\operatorname{Px}_{1} \mathrm{y}_{1}$ in Fig. 4). This mid-plane locking condition is applied only when 


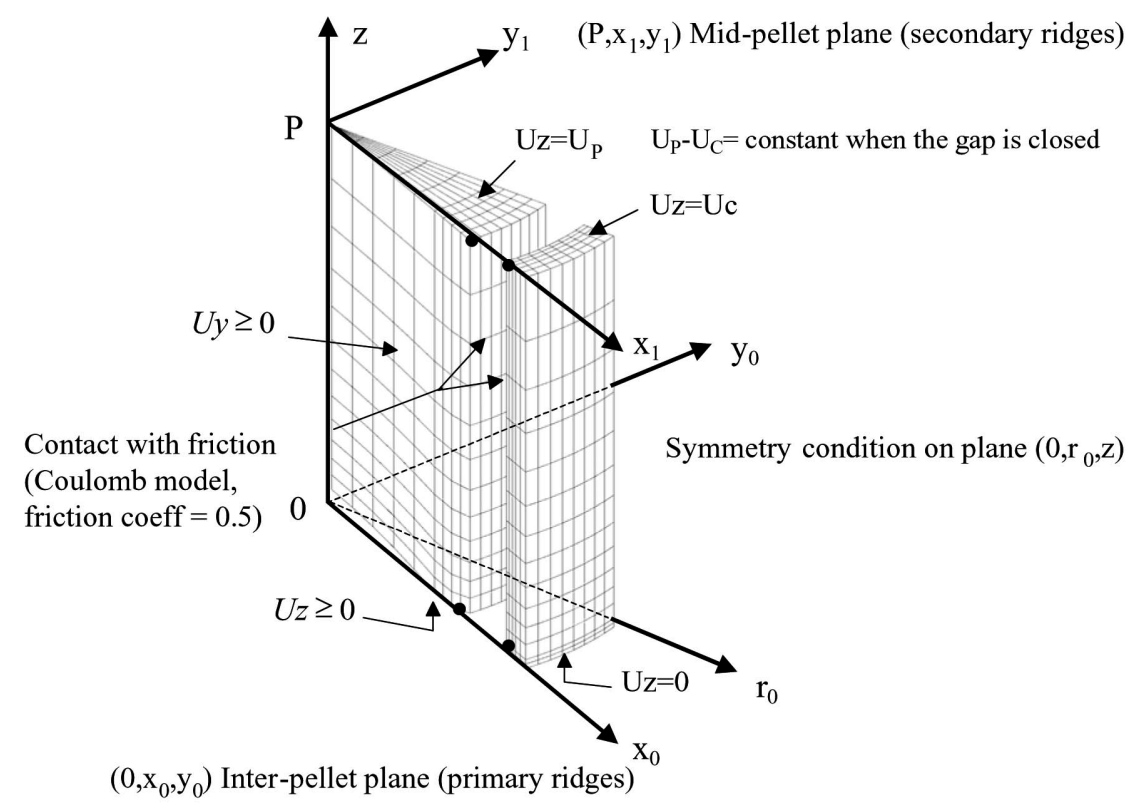

Fig. 4. Mesh and Boundary Conditions in the ALCYONE 3D Simulations

the pellet cladding gap is closed at least at one point. Pelletpellet inter-penetration along the fracture plane $0 \mathrm{x}_{0} \mathrm{Z}$ is forbidden by the unilateral contact condition $\mathrm{Uy} \geq 0$. Concerning the loading conditions, the internal pressure (gas pressure) is applied to the cladding inner surface and to the pellet fragment outer surface. The external pressure (water pressure) is applied to the cladding outer surface.

The phenomena and models implemented in the ALCYONE 3D application are identical to those of the METEOR 1D code except for the relocation, which stems directly from the thermo-mechanical behaviour of the pellet-cladding fragment and for fuel cracking which is described by an elasto-plastic softening law with the $\mathrm{r}, \theta$ and $\mathrm{z}$ axis as the principal cracking directions [7]. Closing of cracks is taken into account during reverse loading. Concerning the pellet-cladding interface, unilateral contact is assessed and a "Coulomb" model introduced to simulate friction-slip or adherence. The latter is of primary importance with respect to stress concentration in the cladding [11-13]. Due to the liner, which tends to reduce friction, a "low" coefficient of friction of 0.5 is used in the simulations (graphite coatings were found to reduce the friction coefficients from $0.7-0.9$ to $0.15-0.3$ in bare Zircaloy [13]).

\section{METEOR 1D SIMULATIONS}

The diameter profiles obtained with METEOR at the end of the base irradiations and after the ramp tests for the KKL1, KKL2 and KKL3 fuel rods are compared in Figs. 5-7 to the experimental profilometries. Good agreement

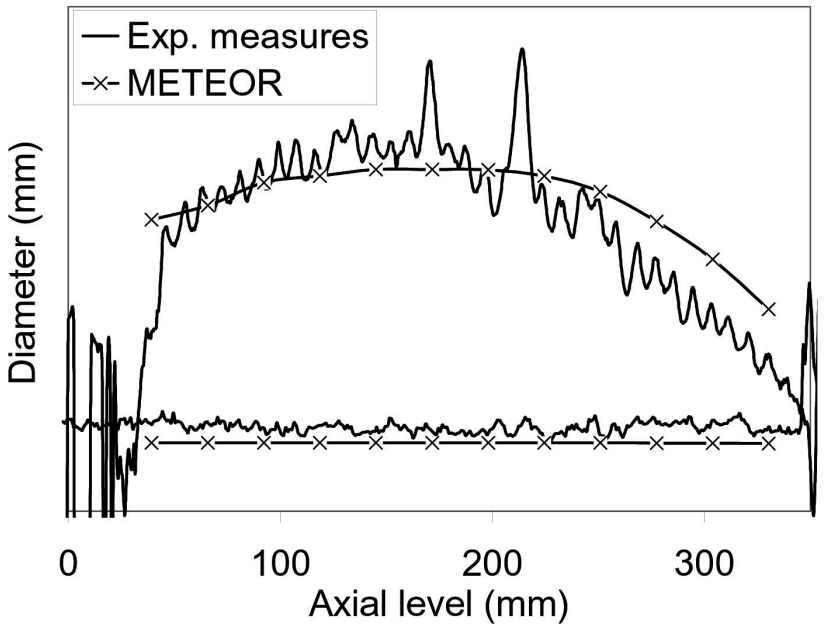

Fig. 5. KKL1 Diameter Profiles Obtained with METEOR

between the experimental and calculated diameter profiles was found for the three fuel rods. $20 \mu \mathrm{m}$ was added to the initial KKL2 and KKL3 cladding external diameters to simulate precisely the diameter profiles after base irradiation. The residual cladding diameters after the ramp tests were correctly estimated by METEOR and rely mainly on both the $\mathrm{Zy}-2$ creep and plasticity models for the KKL1 and KKL3 rods but only on the Zy-2 plasticity model for the KKL2 rod (short holding period). Table 2 illustrates this point by showing the contribution of each 


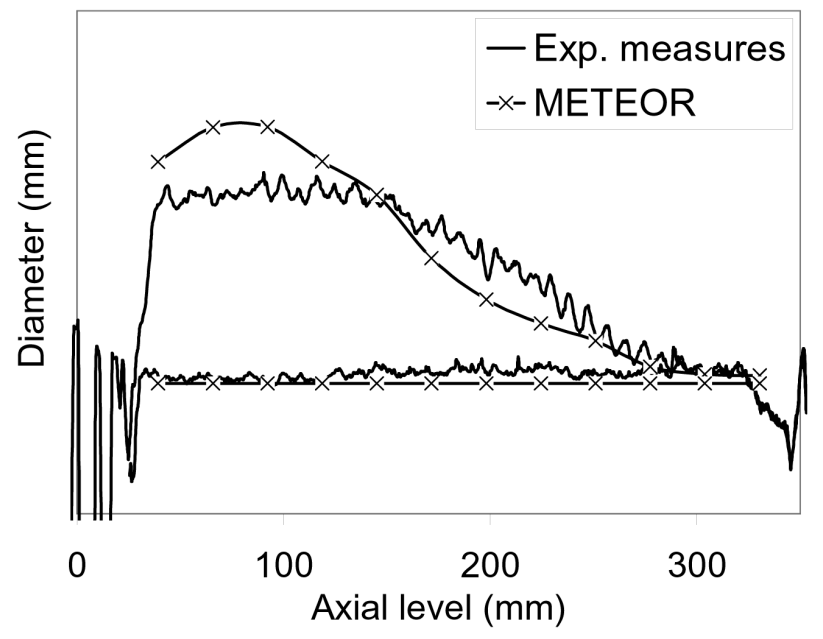

Fig. 6. KKL2 Diameter Profiles Obtained with METEOR

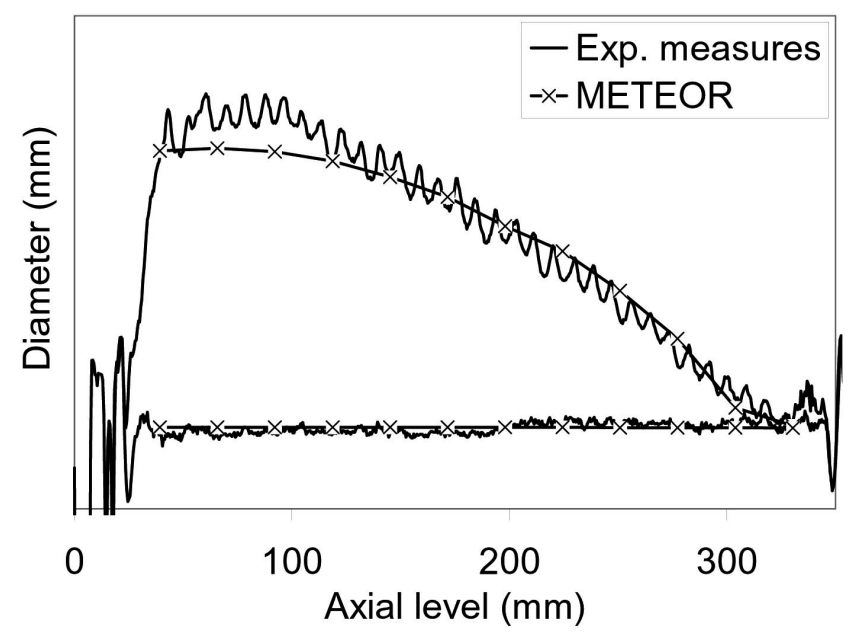

Fig. 7. KKL3 Diameter Profiles Obtained with METEOR

mechanism to the maximum hoop strain at the beginning of the holding periods.

The diameter increases of the KKL1 and KKL3 fuel rods during the ramp tests depend mainly on the FGinduced swelling of the pellet and hence on the FG model. The FG releases obtained with METEOR are summarized in Table 3 together with the experimental measures when available. Surprisingly, the fission gas releases of the KKL1 and KKL2 fuel rods obtained with METEOR are identical $(11 \%)$ in spite of the differences in the power ramp tests. A careful analysis of gas location in the fuel pellets reveals however that the distribution of the gas between intra-granular, inter-granular and connected pores differs considerably for the KKL1 and KKL2 fuel rods.
Table 2. Contribution of Creep and Plasticity to the Maximum Hoop Strain at the Beginning of the Holding Period

\begin{tabular}{l|c|c|c}
\hline Ramp (holding) & KKL1 & KKL2 & KKL3 \\
\hline Max. hoop strain in cladding (\%) & 2.18 & 2.2 & 2.4 \\
Creep (\%) & 0.8 & 0.06 & 1.0 \\
Plasticity (\%) & 0.6 & 1.34 & 0.6 \\
\hline
\end{tabular}

Table 3. Fission Gas Releases Obtained with METEOR and by Post-ramp Examination of the Rodlets

\begin{tabular}{l|c|c|c}
\hline Fission Gas release (\%) & KKL1 & KKL2 & KKL3 \\
\hline METEOR & 11 & 11 & 22 \\
Experimental & $/$ & $/$ & 21.7 \\
\hline
\end{tabular}

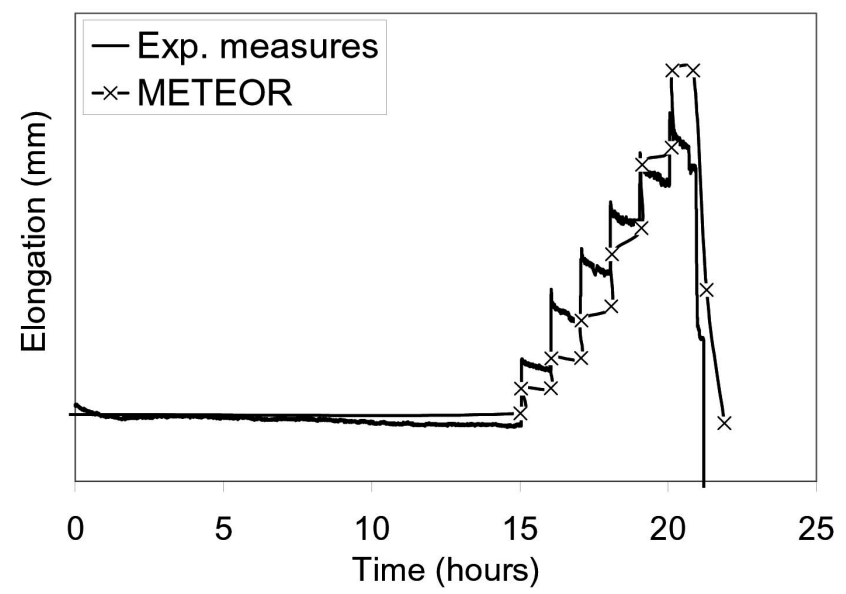

Fig. 8. KKL1 Rod Elongation during the Ramp Test

While the percentage of gas located in intra-granular pores evolved by only $9 \%$ during the KKL 2 ramp test, nearly $20 \%$ of it migrated to inter-granular and connected pores during the KKL1 ramp test. The fission gas release of the KKL3 fuel rod is logically higher $(22 \%)$ than that of the KKL1 and KKL2 fuel rods due to the 12-hour holding period at $520 \mathrm{~W} / \mathrm{cm}$. This is consistent with the post-ramp analysis of the rodlet.

Finally, the rod elongations obtained from the METEOR simulations are presented in Figs. 8-10 together with online measurements. Quantitatively, the KKL1 and KKL2 rod elongations during the ramp tests are well described by the METEOR simulations. The maximum elongation is estimated with a precision of $\pm 25 \%$. METEOR tends 
however to underestimate the elongation of the KKL3 fuel rod. For the staircase ramp tests (KKL1 and KKL3), the measured cladding elongation tends to decrease during power hold. In contrast, the METEOR results show increasing or stable cladding elongations during power hold. In the calculations, it is assumed that, as soon as the pellet clad gap is closed, the axial deformation of the cladding is equal to that of the pellet. Hence, elongation during the ramp test is mainly related to the FG swelling of the pellet which is predominant at a high power level, as shown in Fig. 8. This explains why the calculated clad elongation increases during power hold. The axial pellet cladding locking condition may not be appropriate in all cases, and some friction-sliding may explain the measured decreasing elongations during power hold.

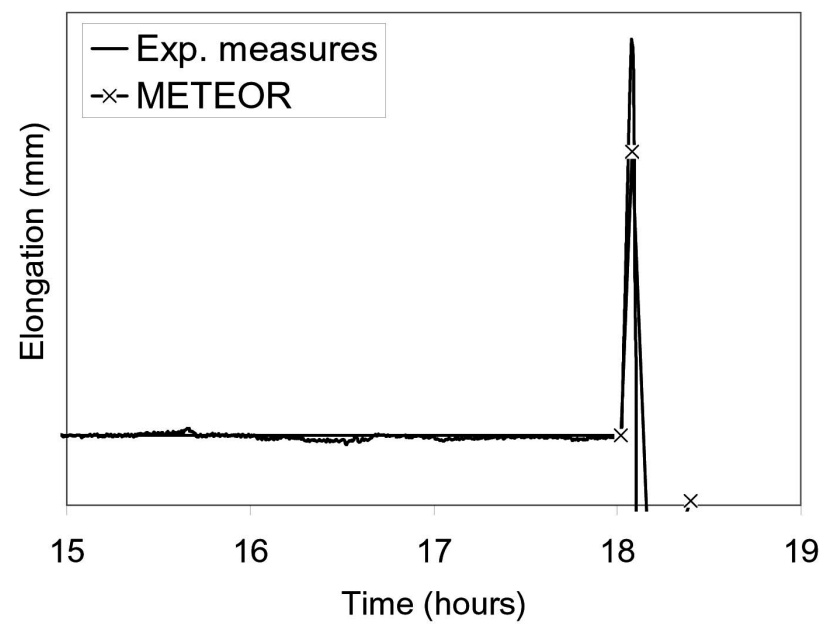

Fig. 9. KKL2 Rod Elongation during the Ramp Test

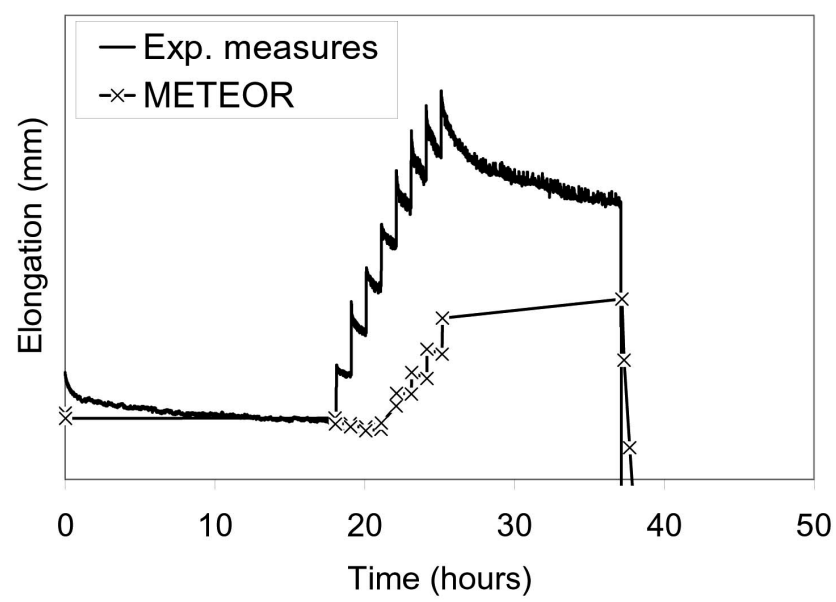

Fig. 10. KKL3 Rod Elongation during the Ramp Test

\section{ALCYONE 3D SIMULATIONS}

Fig. 11 presents the evolution of the internal radius of the cladding and of the external radius of the pellet during base irradiation of the KKL1 rodlet, as obtained from the METEOR 1D and ALCYONE 3D simulations. The 3D results obtained from the thermo-mechanical analysis of the pellet fragment described in Fig. 4 are very close to those of the 1D radial simulations. During the first three cycles, the 1D pellet external radius is in-between the IP and MP radius of the $3 \mathrm{D}$ calculations. This is due to the relocation of the pellet that is taken into account in the

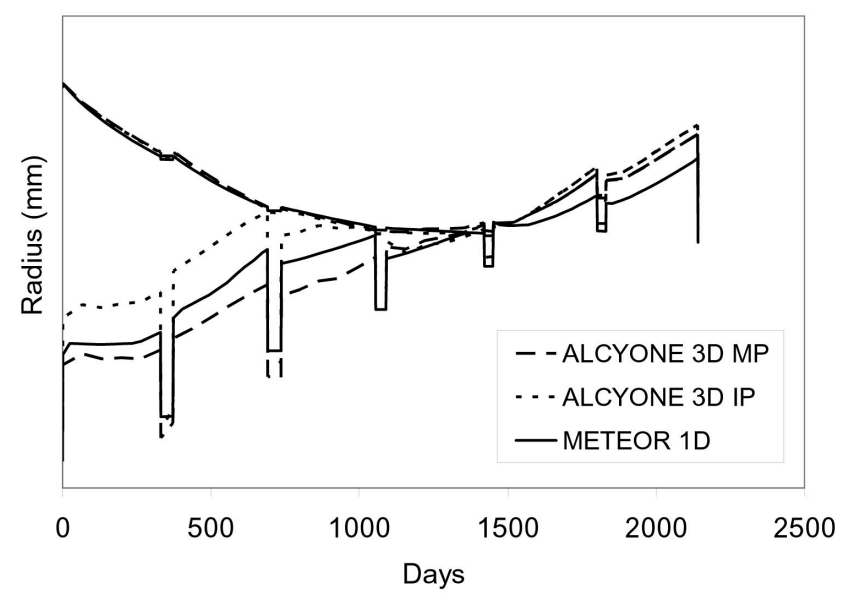

Fig. 11. Internal Radius of the Cladding and External Radius of the Pellet Versus Time during Base Irradiation of the KKL1 Rodlet, as Obtained from ALCYONE 3D (Inter-Pellet and MidPellet Plane) and METEOR 1D

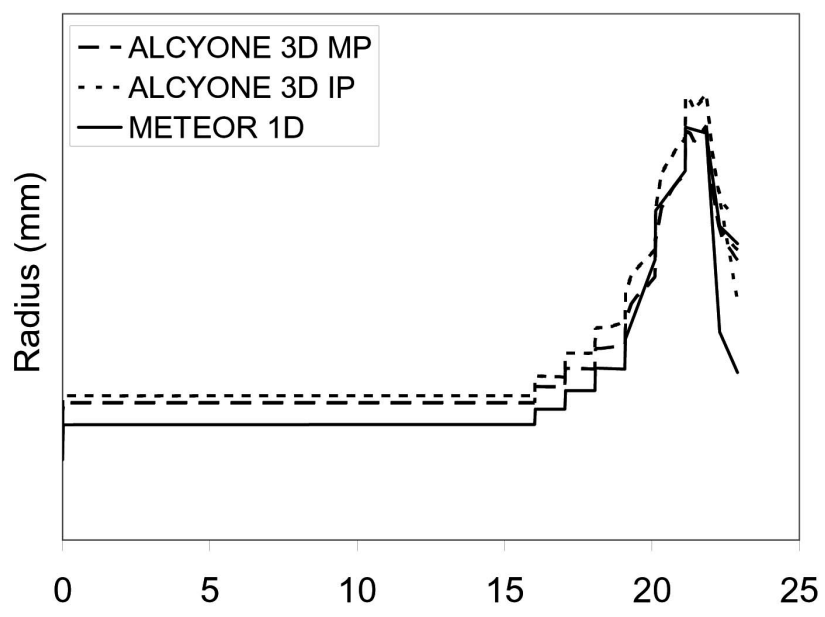

Fig. 12. Internal Radius of the Cladding and External Radius of the Pellet Versus Time during Ramp Test of the KKL1 Rodlet, as Obtained from ALCYONE 3D (Inter-Pellet and Mid-Pellet plane) and METEOR 1D 
METEOR simulations and which models an average 3D hourglass effect. Contact occurs at first at IP level (at the end of the second cycle; see the curve ALCYONE 3D IP) and then at the MP level (third cycle for METEOR; fourth cycle for ALCYONE 3D). The expansion of the pellet-cladding system in the fifth and sixth cycles is then driven by FG-induced swelling, especially in the rim. Small differences in expansion rates are at this point observed between the 1D and 3D simulations. This is due to the mesh refinements in the rim, which are very different (2 elements in 3D, 10 elements in 1D). In consequence, the residual diameters of the pellets and claddings obtained from the 1D and 3D simulations differ by a few microns.

Fig. 12 presents the same curves as in Fig. 11 but

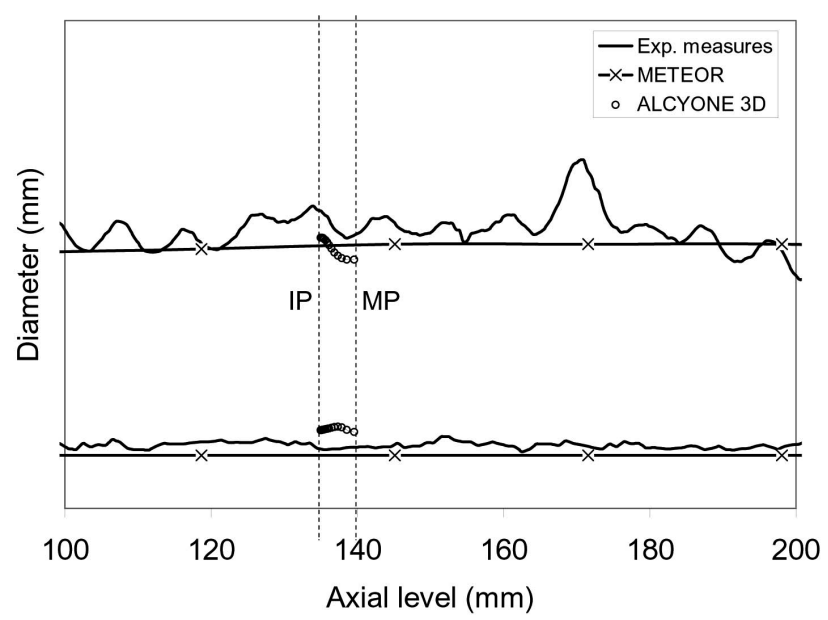

Fig. 13. KKL1 Residual Deformations Obtained with ALCYONE 3D

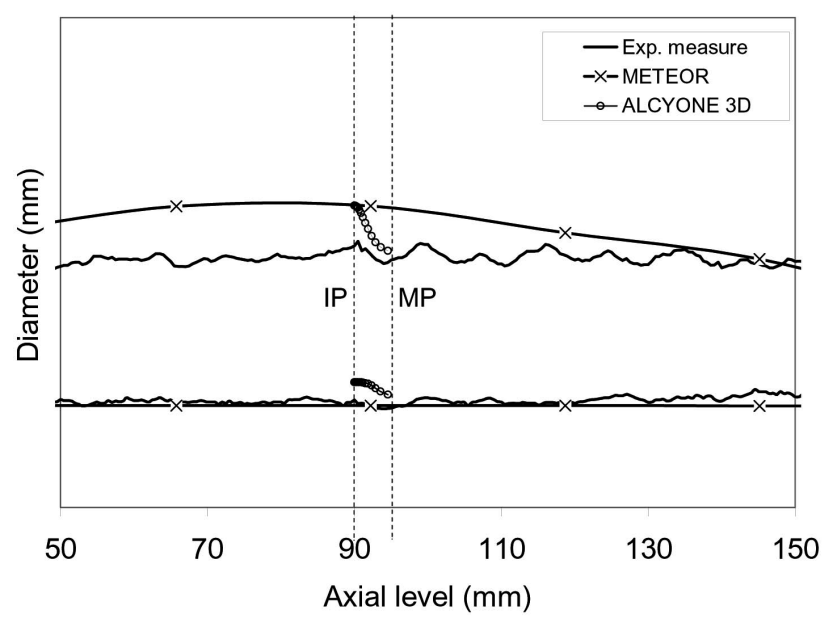

Fig. 14. KKL2 Residual Deformations Obtained with ALCYONE 3D during the power ramp test of the KKL1 rodlet. Except for the differences originating from base irradiation, the 1D and 3D curves show similar patterns with pronounced FG-induced swelling in the fourth and fifth steps of the power ramp test. Similar results were obtained for the KKL2 and KKL3 fuel rods.

The validity of $3 \mathrm{D}$ calculations is usually checked by comparing the residual deformation of the cladding situated at the maximum LHR with the experimental profilometries, as shown in Figs. 13-15. The experimental profilometries after base irradiation present similar patterns with a lack of pronounced primary (IP) and secondary (MP) ridges. These results can be explained 1) by the high

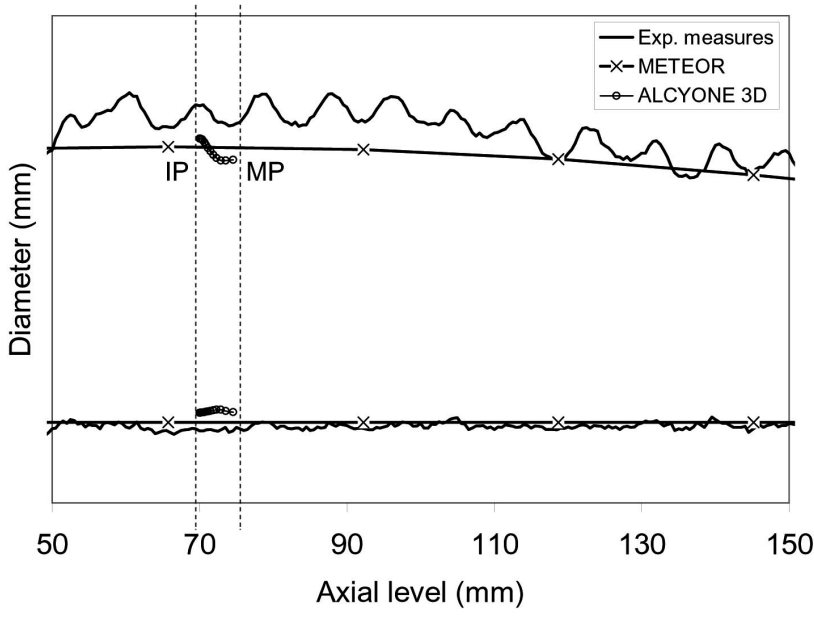

Fig. 15. KKL3 Residual Deformations Obtained with ALCYONE 3D

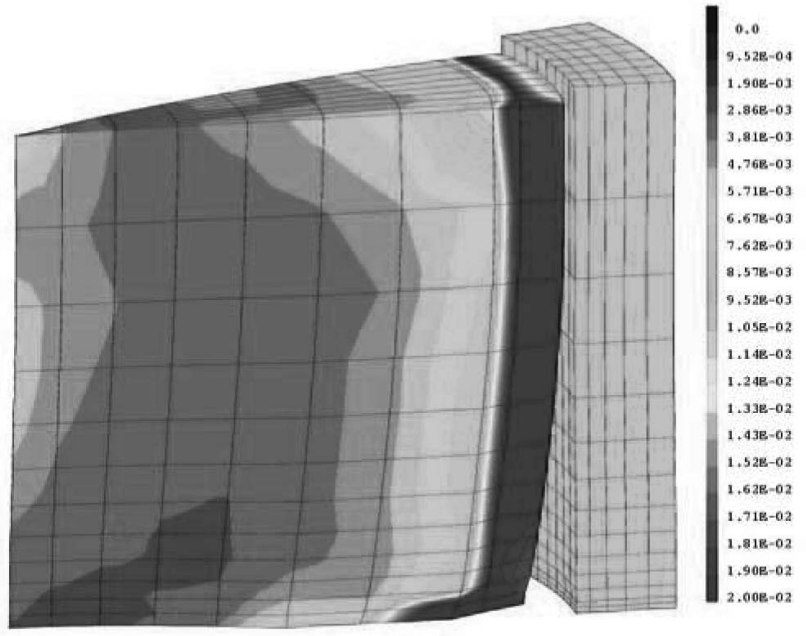

Fig. 16. Residual Strains in the KKL1 Pellet - Cladding System at the End of Base Irradiation Showing the Barrel Shape of the Pellet and the Enhanced FG-Swelling of the Rim 
burn-up of the fuel pellets with a pronounced rim which tends to smooth the radial deformation of the pellet due to the enhanced FG-swelling of the periphery, and 2) by the important number of cycles during base irradiation which leads to a succession of bamboo - barrel pellet shapes with significant axial cracking. These two points are illustrated in Fig. 16. In particular, the peculiar shape of the residual deformations of the cladding at the end of base irradiation showing a maximum at an intermediate axial level between the locations of the IP and MP planes

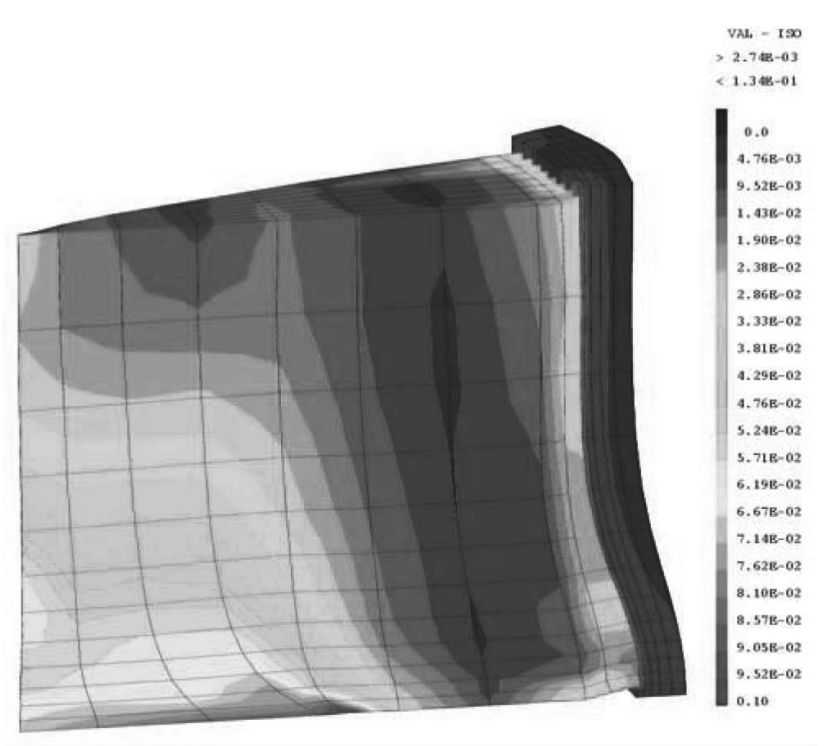

Fig. 17. Residual Strains in the KKL2 Pellet - Cladding System at the Top of the Power Ramp Showing the Viscoplastic Filling-Up of the Dishing

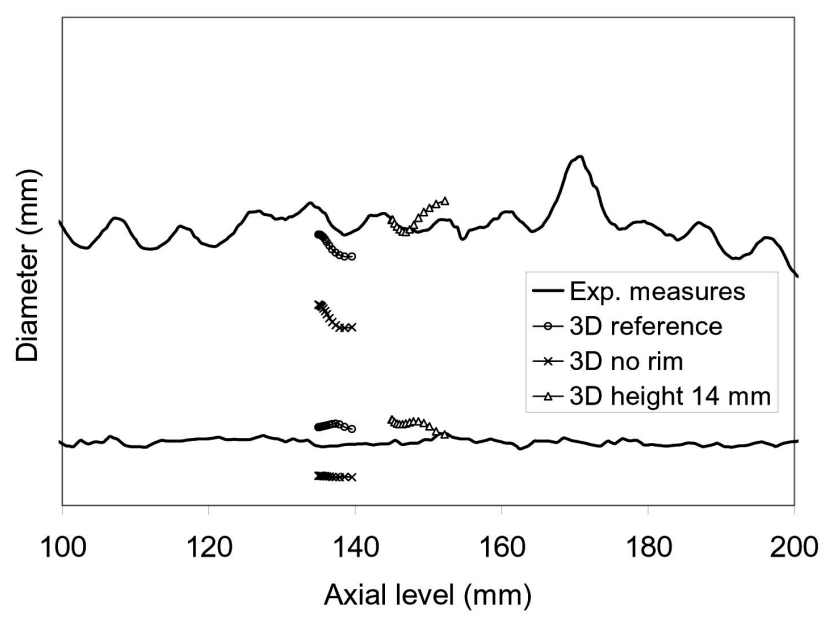

Fig. 18. KKL1 Residual Deformations Obtained from Three Simulations (Reference, with no Rim and with a Pellet Height of $14 \mathrm{~mm}$ ) Performed with ALCYONE 3D can be attributed to the barrel-shape of the pellet after unloading.

The main features of the experimental profilometries after the power ramp tests were also recovered in the ALCYONE 3D simulations. Significant primary ridges (at the IP plane) of 10-20 microns in height were obtained. No secondary ridges (at the MP plane) were observed. The lack of secondary ridges was due to the small height of the pellet $(8.7 \mathrm{~mm})$. For standard PWR fuel rods (pellet height 13-14 $\mathrm{mm}$ ) ramp tested at similar LHRs, the development of secondary ridges is related to the viscoplastic filling-up of the dishing which limits the radial extension of IP ridges and hence increases the constraint at MP plane [14]. When the height over diameter ratio of the pellet is small, as with BWR pellets, the viscoplastic flow at high temperatures towards the dishing occurs in both the radial and axial directions and then tends to limit the development of both IP and MP ridges. This point is illustrated in Fig. 17.

Fig. 18 shows the residual deformation of the cladding obtained for the KKL1 rodlet when the pellet height is 14 $\mathrm{mm}$ instead of $8.7 \mathrm{~mm}$. While this leads to limited differences after base irradiation, it has a significant impact on the profilometry after the ramp test with the development of an important ridge at the MP level. The result of a second calculation in which the specific behaviour of the rim was omitted is also presented in Fig. 18. It is shown that the rim has a strong impact on pellet swelling during base irradiation, leading to a diameter increase of approximately 30 microns. However, this does not occur during the ramp test.

\section{ANALYSIS OF FUEL RODS FAILURE}

It is of common knowledge that failures due to Pellet-Cladding Mechanical Interaction occur at stress

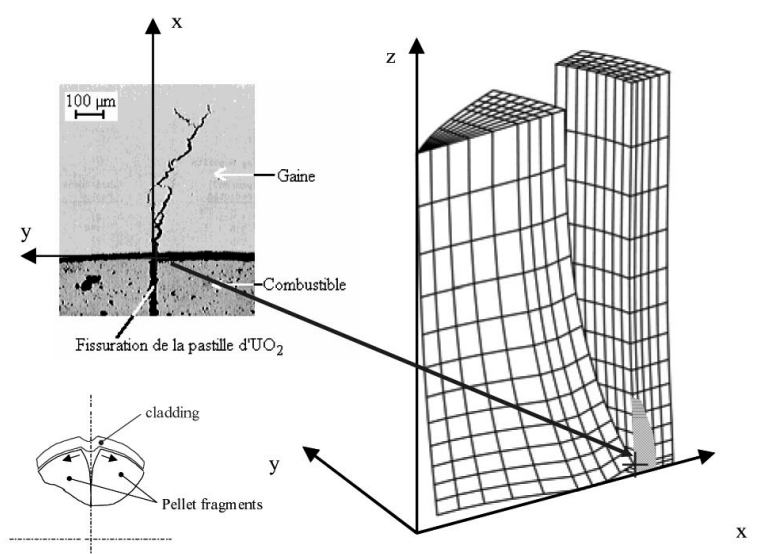

Fig. 19. Schematic Representation and Experimental Observation of Cladding Failure Due to PCMI 
concentration points in the cladding. As illustrated in Fig. 19, cladding failures are usually observed in front of a radial crack in the pellet and at an axial position corresponding to an IP ridge $[13,15]$.

Thus, from a modelling point of view, at least two factors need to be taken into account to simulate cladding failure resulting from PCMI:

- The stress concentration in the cladding due to the punching in front of IP planes induced by the pellet hourglass deformation

- The strain localization in the cladding due to the opening of a pellet crack and the friction at the pellet-cladding interface

A third factor which is not mentioned here would be stress-corrosion acceleration induced by iodine released from the pellet. While the stress localization can be correctly estimated from 3D analyses performed with relatively coarse meshes, such as that plotted in Fig. 4, the strain localization can only be assessed with mesh refinements of the order of the pellet crack openings [16] (10-50 microns). As such refinements are not possible in 3D calculations, a more global failure criterion was recently proposed from the analysis of the normal $\left(\sigma_{n}\right)$ and shear $\left(\sigma_{t}\right)$ stresses at the pellet cladding interface [16]. These stresses are estimated from the equilibrium of nodal forces resulting from the Coulomb friction model according to equations 1 .

$$
\begin{aligned}
& {\left[\sigma_{n}\right]=\frac{[\vec{f}][\vec{r}]}{\int_{S}[N(x, y, z)] d s}} \\
& {\left[\sigma_{t}\right]=\left|\frac{[\vec{f}][\vec{\theta}]}{\int_{S}[N(x, y, z)] d s}\right|}
\end{aligned}
$$

Here, [] is a symbolic definition of a nodal vector, $\vec{f}$ is the nodal force at the pellet cladding interface, $\vec{r}, \vec{\theta}$ denote the unit radial and circumferential vectors, $\mathrm{N}(\mathrm{x}, \mathrm{y}, \mathrm{z})$ is the finite element interpolation functions and $\mathrm{S}$ the inner cladding surface. Typical isovalues of the normal and shear stresses on the inner cladding surface of a PWR fuel rod obtained at the end of the transient part of a ramp test (similar to the KKL2 ramp test) are presented in Fig. 20. The location of the IP plane punching is clearly visible in Fig. 20 left and leads to a normal stress concentration constant in the azimuthal direction. The shear stress (Fig. 20 right) is also at its maximum in front of the IP plane but is localized in the part of the cladding in contact with the tip of the pellet fracture. This result is consistent with the location of cladding failures due to PCMI. It is also consistent with the beneficial effect of a liner which tends to reduce friction at the pellet-cladding interface and

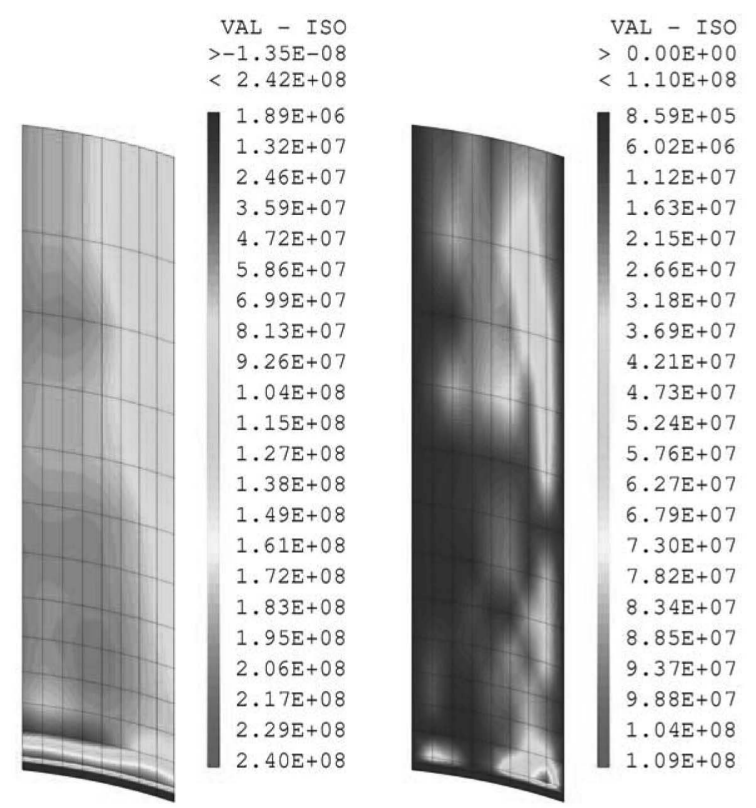

Fig. 20. Isovalues of the Normal (Left) and Shear (Right) Stresses (in Pa) on the Inner Surface of the Cladding of a PWR Fuel Rod Obtained at Maximum LHR during a Power Ramp Test [13]

hence limit shear stresses. Hence, the magnitude of the shear stresses at the pellet - cladding interface can be used as an indicator of the failure probability due to PCMI.

It was also shown recently [16] that $\mathrm{UO} 2$ pellets with reduced tensile strength and fracture energy lead to enhanced cracking during power ramp testing, which in turn has a beneficial effect with respect to PCMI by limiting the shear stresses at the PC interface.

In the next part, the cracking patterns, the normal and shear stresses in the KKL ramp tests will be analyzed to confirm whether the failure of the KKL1 rodlet can be explained by PCMI. The normal stresses on the inner surface of the KKL claddings obtained at the LHR of 420 W/cm during power ramp testing are presented in Fig. 21. The comparison was made at $420 \mathrm{~W} / \mathrm{cm}$, as all of the rods were ramp tested at least up to this level. The distribution of normal stresses is identical for the three KKL rods with maximum values of approximately $200 \mathrm{MPa}$.

The distribution of shear stresses at the same LHR is presented in Fig. 22. The magnitude and distribution of the shear stresses at $420 \mathrm{~W} / \mathrm{cm}$ are notably different from one rod to another. KKL1 reaches a maximum of 93 MPa located at the intersection of the IP plane and the pellet fracture plane. The localization is less pronounced for the KKL2 rod with a maximum shear stress of $52 \mathrm{MPa}$. In between is the KKL3 rod with a maximum shear stress of $62 \mathrm{MPa}$. The higher shear stresses for the KKL1 rodlet cannot be explained by reduced radial cracking during ramp testing, as shown in Fig. 23, where it appears that 


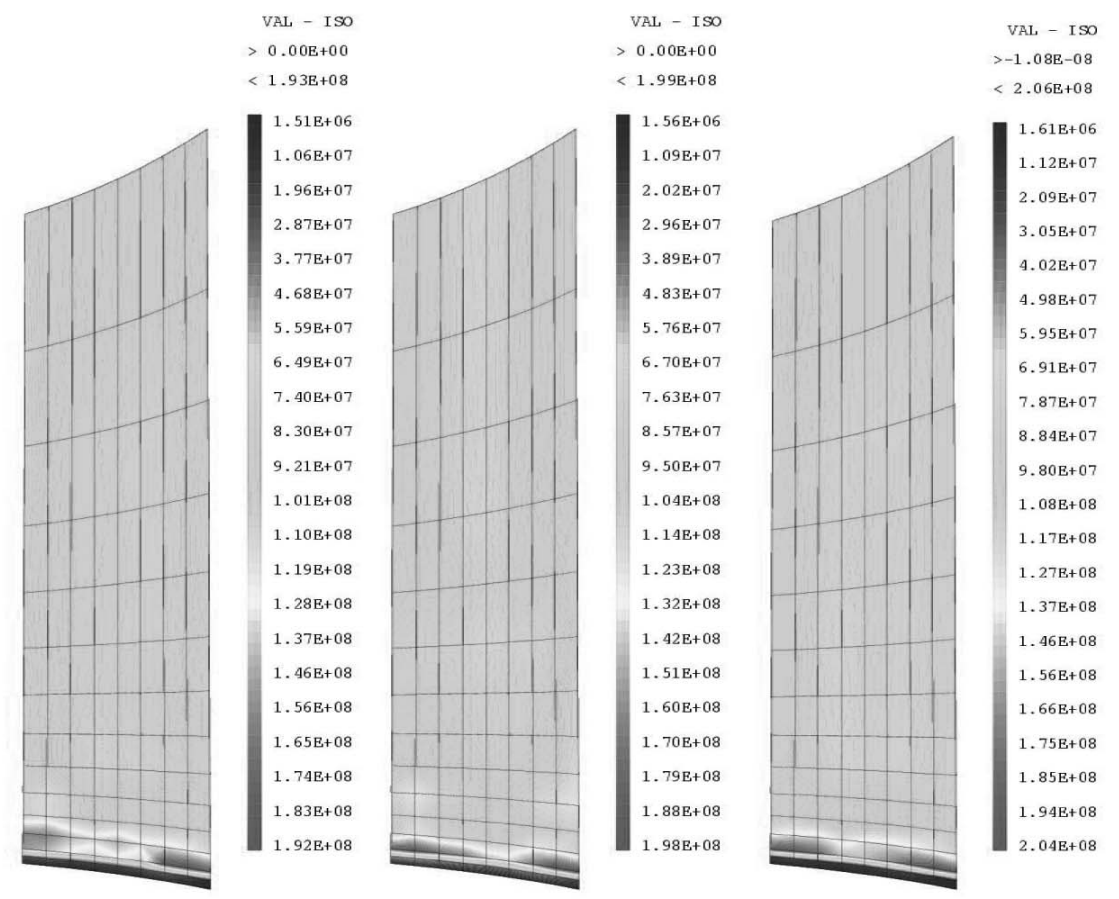

Fig. 21. Isovalues of the Normal Stresses (in Pa) on the Inner Surface of the Cladding of the KKL1 (Left), KKL2 (Middle) and KKL3 (Right) Rodlets at the LHR 420 W/cm during the Power Ramp Tests

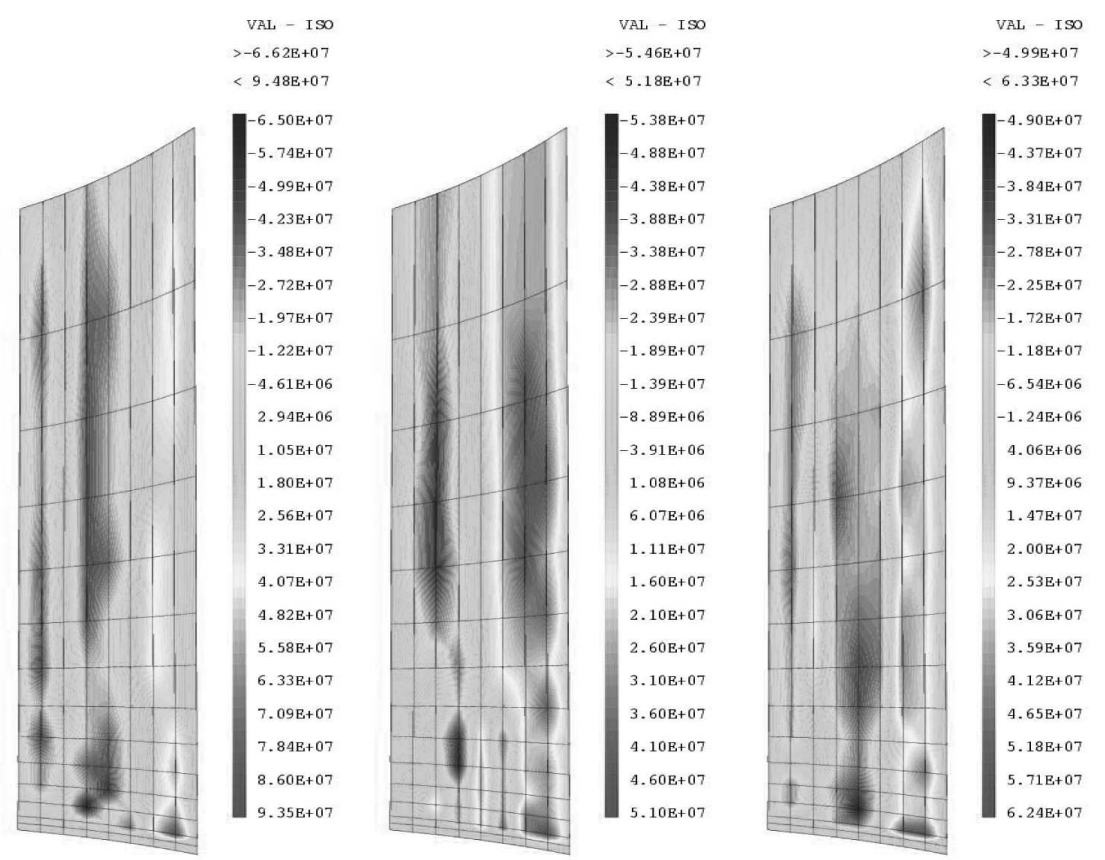

Fig. 22. Isovalues of the Shear Stresses (in Pa) on the Inner Surface of the Cladding of the KKL1 (Left), KKL2 (Middle) and KKL3 (Right) Rodlets at the LHR $420 \mathrm{~W} / \mathrm{cm}$ during the Power Ramp Tests

the distribution of cracking strains at maximum power is comparable for the three KKL rods. The difference in maximum shear stresses between the KKL1 and KKL3 rods is rather due to the more important number of base irradiation cycles for the KKL1 rod, which leads to a stronger pellet cladding interaction at the beginning of 


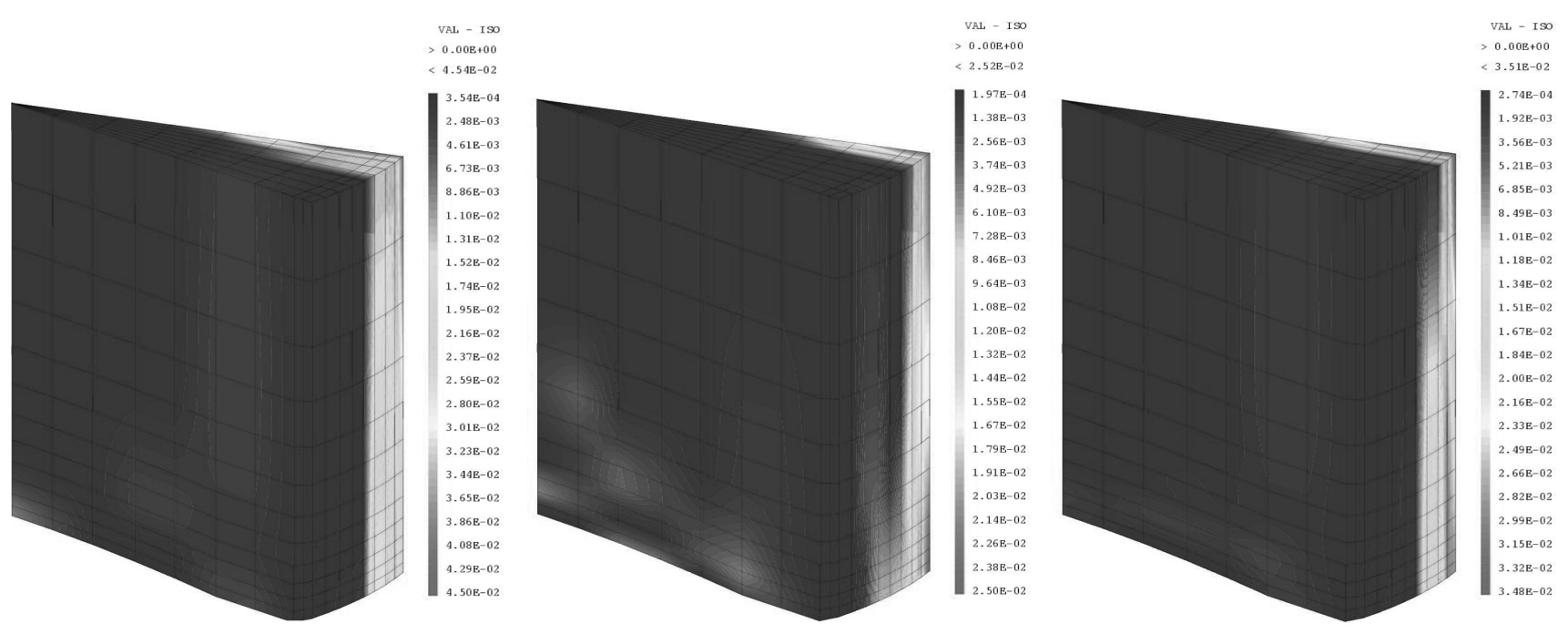

Fig. 23. Radial Cracks Obtained for the KKL1 (Top), KKL2 (Middle) and KKL3 (Bottom) Rodlets at a LHR of 420 W/cm during Power Ramp Testing

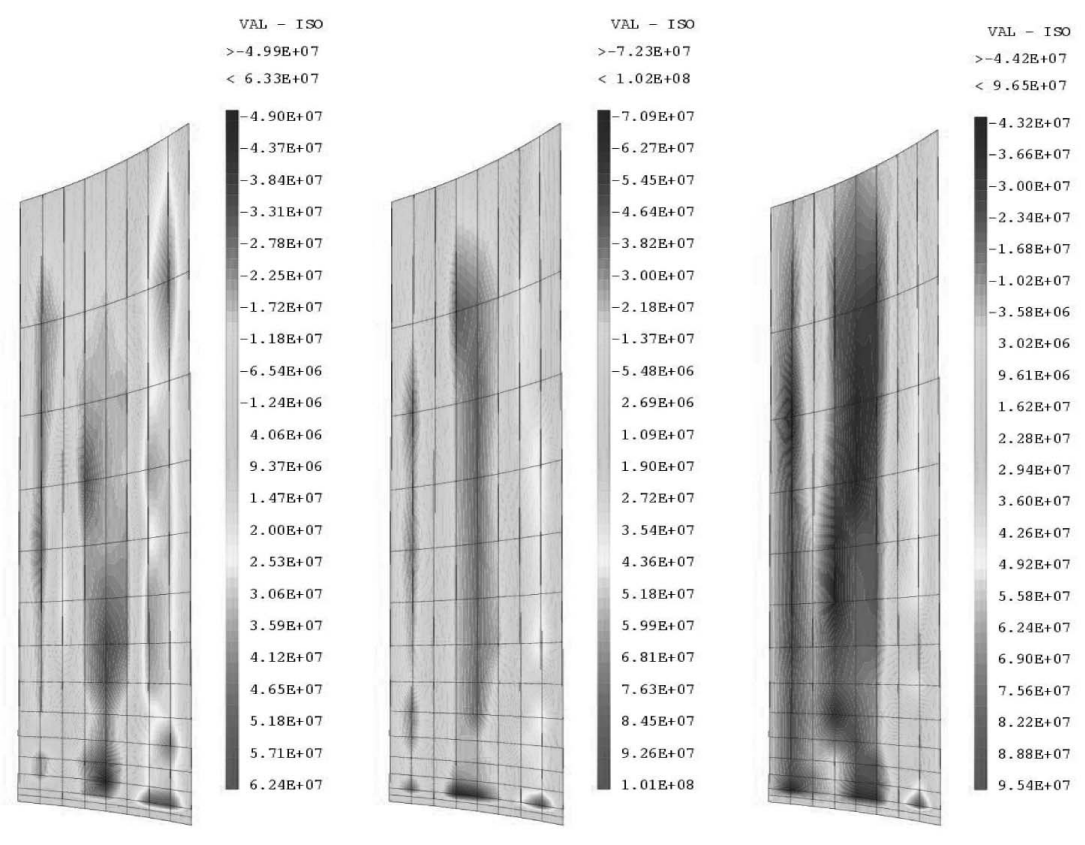

Fig. 24. Isovalues of the Shear Stresses (in Pa) on the Inner Surface of the Cladding of the KKL3 Rodlet at LHRs of 420 (Left), 470 (Middle) and 520 (Right) W/cm during the Power Ramp Tests

the power ramp test. Thus, the results of the simulations are consistent with the fact that the KKL1 rodlet failed at $420 \mathrm{~W} / \mathrm{cm}$. However, when the isovalues of shear stresses for the KKL3 rodlet are considered at the ramp steps of 470 and $520 \mathrm{~W} / \mathrm{cm}$, as illustrated in Fig. 24, this conclusion is less obvious because the maximum value exceeds 100 $\mathrm{MPa}$. Based on these results, the failure of the KKL3 rodlet would then have been expected. This appears to confirm the visual inspections of the cladding performed at Studsvik, as shown in Fig. 25, which indicated that the KKL1 crack started from the external surface of the cladding most likely due to DHC and not solely related to PCMI.

\section{CONCLUSIONS}

In this paper, $1 \mathrm{D}$ and $3 \mathrm{D}$ simulations of power ramp 


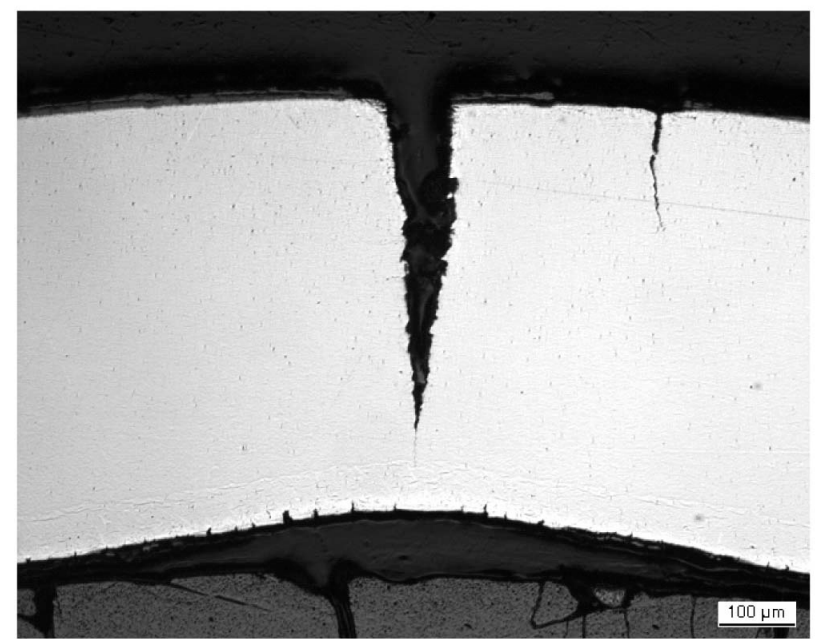

Fig. 25. Cross Section of the KKL1 Cladding after Ramp Testing

tests performed on BWR fuel rods within the Studsvik Cladding Integrity Program have been presented. The METEOR 1D fuel code was used successfully to assess the profilometries of the complete fuel rods and the Fission Gas release. The ALCYONE 3D application, based on the same models as the 1D fuel code, was then applied to the simulation of the behavior of a single pellet fragment situated axially at the position of the maximum LHR. The residual deformations of the cladding obtained from the simulations are consistent with experimental observations. No significant ridges appear after base irradiation due to the high number of cycles and due to the rim of the pellet, which tends to smooth the overall deformation of the pellet-cladding system. Inter-Pellet ridges of 10-20 microns were obtained after power ramp testing. The lack of MidPellet ridges is associated with the small height over diameter ratio of the pellets, which tends to increase axial creep towards the dishing. Finally, the shear stresses at the pellet cladding interface were analyzed to assess the failure probability of the fuel rods. As the KKL1 rodlet that failed during the ramp test did not present higher shear stresses compared to the other rodlets, it cannot be concluded from the simulations that the failure originated solely from Pellet Cladding Mechanical Interaction. This appears to match the post-ramp observations made at Studsvik indicating that the crack in the KKL1 rodlet started from the outer surface of the cladding most likely due to Delayed Hydrogen Cracking.

\section{REFERENCES}

[ 1 ] A.-M. Alvarez Holston, K. Kitano, Källström R., Wikmark G., Arimescu I., Schrire D., "Cladding mechanical assessment and application in modelling”, Top Fuel 2006, Salamanca, Spain (2006).

[2 ] Källström R., "SCIP, Task 0; Ramp test results", Report Studsvik-SCIP-42 (2005).

[ 3 ] Struzik C., Moyne M., Piron J.-P., "High burn-up modelling of UO2 and MOX fuel with METEOR/TRANSURANUS version 1.5", ANS International Topical Meeting on Light Water Reactor Fuel Performances, Portland (1997).

[4] Thouvenin G., Michel B., Sercombe J., Plancq D., Thévenin P., "Multidimensional modeling of a ramp test with the PWR fuel performance code ALCYONE", International Meeting on LWR Fuel Performance, San Francisco, USA (2007).

[ 5 ] Bentejac F., "TOUTATIS an application of the CAST3M finite element code for PCI three dimensional modeling", International seminar on PCI, Aix en Provence, France (2004).

[ 6 ] Plancq D., "PLEIADES: a unified environment for multidimensional fuel performance modelling", International Meeting on LWR Fuel Performance, Florida (2004).

[ 7 ] Michel B., Sercombe J., Thouvenin G., Chatelet R., « 3D fuel cracking modelling in pellet cladding mechanical interaction", Engineering Fracture Mechanics 75, 35813598 (2008).

[ 8 ] Michel B., "3D Fuel Modelling: Multi physic coupling formulation between gaseous swelling and mechanical behaviour", in preparation (2009).

[9] Ledergerber G., Abolhassani S., Limbäck M., Lundmark R.J., Magnusson K.A., " Characterization of high burn up fuel for safety related fuel testing », Journal of Nuclear Science and Technology, 43 (9), 1006-1014 (2006).

[10] Garcia P., Struzik C., Agard M., Louche V., « Monodimensional mechanical modelling of fuel rods under normal and off-normal operating conditions ", Nuclear Eng. And Design, 216, 183-201 (2002).

[11] Roberts G., "The concentration of stress in cladding produced by the expansion of cracked fuel pellets", Nuclear Eng. And Design, 47, 257-266 (1978).

[12] Brochard J., Bentejac F., Hourdequin N., Seror S., Verdeau C., Fandeur O., Lansiard S., Verpeaux P., "Modelling of Pellet Cladding Interaction in PWR fuel", Transactions of SMIRT 16, Washington DC (2001).

[13] Cox B., « Pellet-Clad Interaction (PCI) failures of zirconium alloy fuel cladding - a review", Journal of Nuclear Materials, 172, 249-292 (1990).

[14] Nonon C., Lansiart S., Struzik C., Plancq D., Martin S., Decroix G.M., Rabouille O., Beguin S., Julien B., « Differential $P C I$ behaviour of PWR fuel rods under transient conditions », Proc. Of the Int. Meeting on LWR Fuel Performance, Orlando, USA (2004).

[15] Mougel C., Verhaeghe B., Verdeau C., Lansiart S., Béguin S., Julien B., " Power ramping in the Osiris reactor : database analysis for standard UO2 fuel with Zy-4 cladding", Proc. Of the Pellet-clad Interaction in Water Reactor Fuels Seminar, Aix-en-Provence, France (2004).

[16] Michel B., Sercombe J., Thouvenin G., « A new phenomenological criterion for Pellet Cladding Interaction rupture", in Press, Nuclear Eng. and Design, 238, 16121628 (2008). 